\title{
Multi-port converter for medium and high voltage applications
}

\author{
F. Alsokhiry and Y. Al-Turki \\ King Abdulaziz University, \\ Jeddah, Kingdom of Saudi Arabia
}

\author{
Ibrahim Abdelsalam \\ Arab Academy for Science and \\ Technology and Maritime \\ Transport, Cairo, Egypt
}

\author{
G.P. Adam and K.H. Ahmed \\ University of Strathclyde \\ grain.adam@strath.ac.uk
}

\begin{abstract}
This work presents a multi-port converter (MPC) that is well-suited for use as a hybrid hub in complex multiterminal high-voltage direct current (MTDC) networks. The proposed MPC generates several and controllable DC voltages from a constant or variable input DC voltage or AC grid. Its operating principle is explained and corroborated using simulations and experimentations.
\end{abstract}

Key words-DC-DC converters for future DC grids; hybrid DC-DC and DC-AC hubs; DC power and voltage control, and auto DC transformers

\section{INTRODUCTION}

MTDC grids represent the initial step for realisation of future super grids to facilitate bulky powers transfer over long distances, with tight control over the directions and magnitudes of the power transfer in each DC line[1-7]. Such MTDC systems are anticipated to consist of more than one DC voltage levels[8-13]. The DC voltage magnitude of each section will be dictated by the magnitude of power to be transferred and DC cables ratings. In MTDC grids, DC transformers are anticipated to play important roles such as DC voltage and power control, and definition of protection zones, where galvanic isolation and DC fault containment are essential[14-16].

In recent years, a number of isolated and non-isolated DC transformers were suggested for possible use in MTDC grids [17-20]. Most of the existing isolated DC transformers have adopted the basic circuit structure of the dual active bridge (DAB) or front-to-front $(\mathrm{F} 2 \mathrm{~F})$ connected AC/DC converters. These DC transformers capable of stopping propagation of DC fault outside the faulted DC side. Such attribute could be utilized to decrease the amount of DC circuit breakers and to split large MTDC grids into a number of self-contained isolated DC networks. The major weakness of the F2F DC transformers is that the $\mathrm{HV}$ and $\mathrm{LV}$ converters and isolation AC transformer are sized for full power, and this decreases their efficiencies.

In an attempt to decrease the cost, size and weight of the F2F DC transformers, the work in [21] operates the MMC based DC transformer in a quasi-two-level (Q2L) mode. This work has shown that the Q2L-MMC based DC transformer exposes the isolating transformer to a low and controllable $d v / d t$. Also, it reduces the submodule capacitance, arm inductance and current rating of the semiconductor switches of the half-bridge submodule (HB$\mathrm{SM})$, particularly, the switches that insert the sub-modules' capacitors into the power path.

Further reduction in the capital cost and footprint of MMC based F2F DC transformer is achieved through adoption of the transition arm converter (TAC)[22].

Many works have promoted the non-isolated F2F DC transformers as alternative to isolated version, particularly, to reduce cost, weight and losses. Although the non-isolated DC transformer can contain the impact of pole-to-pole DC short circuit faults within the faulty side, it is unable to contain the impact of pole-to-ground, particularly, the substantial shift of the insulation level of the healthy pole.

The most promising partially isolated DC transformer with circuit structure resembles auto transformer was proposed in [19]. Its main attributes are: the rated power could be exchanged between the HV and LV sides, and the same time the semiconductor switches of the LV side and isolation transformer that connects upper and lower subconverters $\left(\mathrm{SC}_{1}\right.$ and $\left.\mathrm{SC}_{2}\right)$ are fractionally rated. Numerous variations of this auto DC transformer are discussed in [19]. Nonetheless, the immense potentials exist in the DC transformers in [19] are not fully exploited. From DC fault ride-through viewpoint, the asymmetric monopole nature of $\mathrm{SC}_{1}$ and $\mathrm{SC}_{2}$ makes the DC transformer in in [19] to DC faults; especially, as any DC fault that may occur in its DC side resembles pole-to-pole DC short-circuit fault. For examples, a pole-to-ground DC fault in the positive pole creates a short circuit fault across $\mathrm{SC}_{1}$, while a pole-toground $\mathrm{DC}$ fault in the negative pole creates a short circuit fault across $\mathrm{SC}_{2}$.

In [17], numerous non-isolated buck and boost hybrid cascaded DC transformers are proposed for HVDC applications. In these DC transformers, the FB cells in each limb are used to filter-out the deliberately injected AC components in order to generate any desired DC voltage magnitude from a fixed input DC voltage. The absence of AC transformers in the hybrid cascaded DC transformers in [17] is advantageous as this leads to cheaper and lighter DC transformers than those presented in [19]. However, the major deficiency of these topologies is that the series connected switches and FB stack of each limb should be designed to sustain the rated pole-to-pole DC voltage of the HV side when a DC short circuit fault happens at the LV side. This sacrifices the overall system efficiency. It worth emphasizing that the DC transformers in [17] are applicable to asymmetrical monopole systems.

Therefore, this work extends the idea of DC autotransformer suggested in [19] to generic MPCs capable of generating several $\mathrm{AC}$ and $\mathrm{DC}$ outputs from a fixed or variable AC or DC voltage. The proposed MPC provides a economical solution for a hybrid hub capable of facilitating: DC voltage and power control in complex DC grids. The basics of the presented MPC is described using two and three-port converters, and validated using simulation and experimental results. Also, this work clarifies the mathematical expressions that determine the $\mathrm{AC}$ and $\mathrm{DC}$ powers of the MPC, further than that explained in [19]. For instance, in the two-port converter, the $\mathrm{AC}$ power of the $\mathrm{SC}_{2}$ determines the current stresses in the switches of the $\mathrm{SC}_{2}$, not the entire DC power of the $\mathrm{SC}_{2}$ as described in[19]. Moreover, it is found that the MPC with large number of ports facilitates better sharing of the power between the subconverters; thus, decreases the rated power of the subconverters and their current ratings. 


\section{MULTI-PORT CONVERTERS}

Fig. 1 presents a number of MPCs capable of operating simultaneously as DC/DC and DC/AC converters in medium and high voltage DC and smart grids to control power and DC voltage, including DC voltage matching and tapping. The presented MPCs evolve from the DC transformers proposed in [19], and these MPCs were developed to facilitate large-scale integration of renewable power generations such as photovoltaic into MVDC and HVDC grids. The current stresses in the switches of the upper and lower sub-converters $\left(\mathrm{SC}_{1}\right.$ and $\left.\mathrm{SC}_{2}\right)$ of the twoports in Fig. 1 (a) vary with the power flow direction and DC voltage ratio. However, the current stresses in the switches of SCs decrease as the number of ports increases. Assuming the power flow and DC current directions shown in Fig. 1 (a) to be positive, the active powers that the SC1 and SC2 exchange with the AC side can be expressed as:

$$
\begin{aligned}
& P_{a c 1}=\frac{3}{2} V_{m 1} I_{m 1} \cos \left(\delta_{1}+\varphi_{1}\right) \approx 3\left(V_{d c 1}-V_{d c 2}\right) I_{d 1} \\
& P_{a c 2}=\frac{3}{2} V_{m 2} I_{m 2} \cos \left(\delta_{2}+\varphi_{2}\right) \approx 3 V_{d c 2} I_{d 2}
\end{aligned}
$$

where, $I_{d 1}$ and $I_{d 2}$ are DC currents in the $\mathrm{SC}_{1}$ and $\mathrm{SC}_{2}$ arms $\left(I_{d 1}=1 / 3 I_{d c 1}\right.$ and $I_{d c 2}=3\left(I_{d 2}-I_{d 1}\right) \approx 3 I_{d 2}-I_{d c 1}, \delta_{1}$ and $\delta_{2}$ are the voltage angles of the $\mathrm{SC}_{1}$ and $\mathrm{SC}_{2} ; \varphi_{1}$ and $\varphi_{1}$ are phase shift between the grid voltage and currents of the $\mathrm{SC}_{1}$ and $\mathrm{SC}_{2}$; and $V_{m 1}$ and $V_{m 2}$, and $I_{m 1}$ and $I_{m 2}$ are the peaks of the AC voltages and phase currents that the $\mathrm{SC}_{1}$ and $\mathrm{SC}_{2}$ present to interfacing transformers and inject into $\mathrm{AC}$ grid. It is worth emphasizing that $I_{d c 2}$ signifies the mismatch between $\mathrm{I}_{d l}$ and $I_{d 2}$ of the $\mathrm{SC}_{1}$ and $\mathrm{SC}_{2}$ should the circulating currents in their arms are well suppressed. On the other hand, $P_{a c l}$ is stated as:

$$
P_{a c 1}=V_{d c 1} I_{d c 1}\left(1-V_{d c 2} / V_{d c 1}\right)=P_{d c 1}(n-1) / n
$$

where, $n=V_{d c l} / V_{d c 2}$ and $P_{d c l}=V_{d c 1} I_{d c 1}$. The total power transfer between the ac grid and $\mathrm{SC}_{1}$ and $\mathrm{SC}_{2}$ shown in Fig. 1 (a $P_{g}$ represents the algebraic sum, i.e., $P_{g}=P_{a c l}+P_{a c 2}$. The peak phase voltages at the AC terminals of the $\mathrm{SC}_{1}$ and $\mathrm{SC}_{2}$ are:

$$
V_{m 1}=1 / 2 m_{1}\left(V_{d c 1}-V_{d c 2}\right)
$$

$V_{m 2}=1 / 2 m_{2} V_{d c 2}$

The current components related with the active power exchange between the AC and DC sides of the $\mathrm{SC}_{1}$ and $\mathrm{SC}_{2}$ are: $\frac{3}{4} m_{1} I_{m 1} \cos \left(\delta_{1}+\varphi_{1}\right) \approx\left|I_{d c 1}\right|$ and $\frac{3}{4} m_{2} I_{m 2} \cos (\delta+\varphi) \approx 3\left|I_{d 2}\right|$.

When the power flow directions in the SC1 and SC2 are from $\mathrm{AC}$ to $\mathrm{DC}$ side (or from the $\mathrm{DC}$ to $\mathrm{AC}$ side), the transformer windings and switching devices of the $\mathrm{SC}_{2}$ experience higher currents s than that of the SC1.

$$
\begin{aligned}
& I_{d 1}=1 / 3\left|I_{d c 1}\right| \\
& I_{d 2}=1 / 3\left|I_{d c 1}\right|+1 / 3\left|I_{d c 2}\right|
\end{aligned}
$$

If the polarity of the power flow in $\mathrm{SC}_{1}$ is opposite to the polarity of the power flow in $\mathrm{SC} 2$, the average DC currents in the arms of the $\mathrm{SC}_{1}$ and $\mathrm{SC} 2$ could be approximated by $I_{d 1}=1 / 3\left|I_{d c 1}\right|$ and $I_{d 2}=1 / 3\left|I_{d c 1}\right|-1 / 3\left|I_{d c 2}\right|$, and the magnitudes of the $\mathrm{AC}$ current components associated with active powers in the transformer windings of the $\mathrm{SC}_{1}$ and $\mathrm{SC}_{2}$ can be expressed by:

$$
\begin{aligned}
& \left|I_{d c 1}\right| \approx \frac{3}{4} m_{1} I_{m 1} \cos \left(\delta_{1}+\varphi_{1}\right) \\
& || I_{d c 1}|-| I_{d c 2} \mid \approx \frac{3}{4} m_{2} I_{m 2} \cos (\delta+\varphi) .
\end{aligned}
$$

On other hand, the expression (8) and above discussions reveal that the switches and transformer windings connected to $\mathrm{SC}_{2}$ will be exposed to reduced currents when the power flows in $\mathrm{SC}_{1}$ and $\mathrm{SC}_{2}$ are in the opposite directions. In this scenario, the power transfer between $\mathrm{SC}_{1}$ and $\mathrm{SC}_{2}$ via the $\mathrm{AC}$ side is:

$$
V_{d c 2}|| I_{d c 1}|-| I_{d c 2}||
$$

When AC and DC sides of the MPC in Fig. 1 (a) are attached to AC and DC grids, AC powers $P_{a c l}$ and $P_{a c 2}$ can be regulated to curb the current magnitudes in $\mathrm{SC}_{1}$ and $\mathrm{SC}_{2}$, independent of $n$. The reason is that $P_{a c l}$ specifies the DC power to be transferred between the $\mathrm{SC}_{1}$ and $\mathrm{SC}_{2}$ through their arms, while bypassing the AC side:

$$
P_{d c l 2} \approx P_{d c l} / n \approx P_{a c l} /(n-1)
$$

Whilst $P_{a c 2}$ specifies the magnitudes of $P_{d c 2}$ to be transferred or provided from the AC side, and currents in the $\mathrm{SC}_{2}$. In this way, the total DC power of the $\mathrm{SC}_{2}\left(P_{d c 2}\right)$ can be sourced via the arms of $\mathrm{SC}_{1}$ and $\mathrm{SC}_{2}$, with $P_{a c 2}=0$ and zero currents on its semiconductor switches of $\mathrm{SC}_{2}$, provided that the ratio $n$ is adequately high to avoid overloading the switches of the $\mathrm{SC}_{1}$.

Fig. 1 (b) presents an illustrative example of MPC that can synthesize several DC voltages, while ensuring that the currents are well-distributed between sub-converters. In the MPC in Fig. 1 (b), the $\mathrm{SC}_{1}$ and $\mathrm{SC}_{2}$ transfer power between their $\mathrm{AC}$ and $\mathrm{DC}$ sides using the same operating principle of the two-port converter explained earlier. Whilst $\mathrm{SC}_{3}$ exchanges power via its AC link only, sharing an $\mathrm{AC}$ power $\left(P_{a c l}\right)$ that the $\mathrm{SC}_{1}$ presents to its $\mathrm{AC}$ side with $\mathrm{SC}_{2}$. Such configuration decreases currents in the $\mathrm{SC}_{2}$ when the threeport converter operates as an auto DC transformer. In this case, when the $\mathrm{SC}_{1}$ is sourcing $\mathrm{AC}$ power $\left(P_{a c l}\right)$ and $\mathrm{SC}_{2}$ and $\mathrm{SC}_{3}$ are both sinking AC powers $P_{a c 2}$ and $P_{a c 3}$, the amount of $\mathrm{AC}$ power to be transferred through $\mathrm{SC}_{2}$ is:

$P_{a c 2}=P_{a c 1}-P_{a c 3}$

Therefore, setting $P_{a c l}$ is enough for full definition of of the total DC power $\left(P_{d c l}\right)$ at high-voltage DC terminal $P_{d c l}=n P_{a c l}(n-1)$, and the magnitude of DC power to be transferred between sub-converters 1 and 2, without passing via the $\mathrm{AC}$ side $\left(P_{d c l} / n\right)$.

When AC side of the three-port converter is attached to the AC grid, the DC power $\left(P_{d c 2}\right)$ of sub-converter 2 is defined by $P_{a c 1}$ and $P_{a c 2}$, with $P_{a c 1}$ defining the power transfer from sub-converter 1 to 2 via the DC side, without passing by the AC side, and $P_{a c 2}$ defines the power transfer from AC side of sub-converter 2 to its DC side:

$$
P_{d c 2} \approx P_{d c 1} / n+P_{a c 2} \approx P_{a c 1} /(n-1)+P_{a c 2}
$$

In both of the above cases, the DC power of $\mathrm{SC}_{3}\left(P_{d c 3}\right)$ is determined exclusively by its AC power $\left(P_{a c 3}\right)$.

In addition to the above discussions, the MPCs in Fig. 1 could be realized by employing different topologies such as two-level converter[23], HB-MMC, FB-MMC and mixed cell $\mathrm{MMC}$ in $\mathrm{SC}_{1}, \mathrm{SC}_{2}$ and $\mathrm{SC}_{3}$. For an example, when the MPC is employed for integration of medium-scale solar power plant that operates at MVDC into HVDC grid, the use of two-level converter in $\mathrm{SC}_{3}$ could be justified. In similar way, other converter topologies could be employed in the $\mathrm{SCs}$ of the MPCs to deliver bespoke features. 


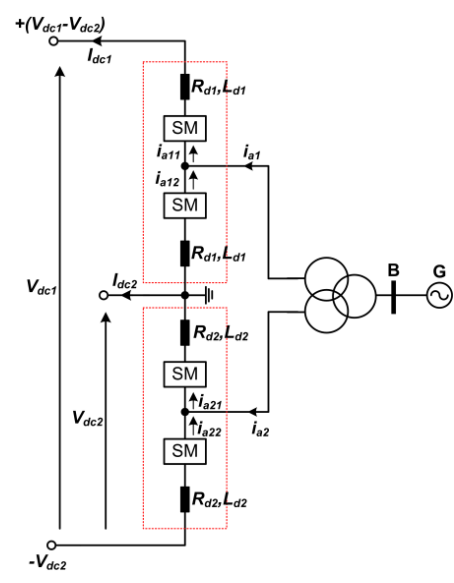

(a)

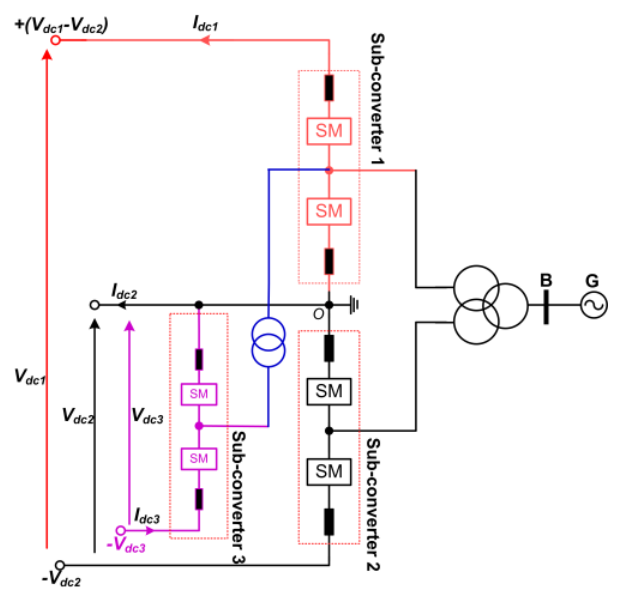

(b)

Fig. 1: Possible configurations of proposed MPCs: (a) Two-port converter and (b) Three-port converter

\section{CONTROL SYSTEMS}

When the AC side of the MPC is connected to AC grid as shown in Fig. 1 (a), the power transfer between its AC and DC terminals are controlled by varying the phase and magnitude of the voltage vectors at the $\mathrm{AC}$ terminals of the $\mathrm{SC}_{1}$ and $\mathrm{SC}_{2}$ relative to $\mathrm{AC}$ that of the $\mathrm{AC}$ grid. The angle difference $\delta_{1}-\delta_{2}$ contributes to definition of the magnitude and direction of the power $P_{a c 2}$ to be exchanged between the $\mathrm{SC}_{1}$ and $\mathrm{SC}_{2}$ via the $\mathrm{AC}$ side, and with the $I_{d c 1} V_{d c 2}=I_{d c l} V_{d c l} / n=P_{d c 1} / n$ defines the DC power that the $\mathrm{SC}_{1}$ and $\mathrm{SC}_{2}$ exchange without passing via the AC side. When $\delta_{1}+\delta_{2}=0$, the net power injected into AC grid is zero; and this means the total AC power of the $\mathrm{SC}_{1}$ is transferred to the $\mathrm{SC}_{2}\left(P_{a c 2}=-P_{a c 1}\right.$, where $P_{a c l}=P_{d c l}(n-1) / n$ and $\left.I_{d c 2}=n I_{d c l}\right)$, resembling the DC auto-transformer operation discussed earlier. When $\delta_{2}-\delta_{1}=0$, zero power will be exchanged between the $\mathrm{SC}_{1}$ and $\mathrm{SC}_{2}$ via the $\mathrm{AC}$ side; instead, the total $\mathrm{AC}$ powers of the $\mathrm{SC}_{1}$ and $\mathrm{SC}_{2}$ will be transferred to $\mathrm{AC}$ grid, but this does not preclude power transfer through the DC side. The above discussions show that the sub-converters of the MPC based MMC can be controlled independently. When the AC side of the two-port converter is attached to an $\mathrm{AC}$ island with no generation (passive load), one of the sub-converters must regulate AC voltage in the $\mathrm{AC}$ link and the other sub-converter can control active power or DC voltage. Recall that setting $P_{a c l}$ is enough for definition of the DC power at the HV DC terminal, $P_{d c l}=n P_{a c l} /(n-1)$ and DC link current $I_{d c l}=P_{d c l} / V_{d c l}=n /(n-1) \times P_{a c l} / V_{d c l}$.

When the SC1 and SC2 have opposite power flow directions and $P_{a c 1}>P_{a c 2}, P_{a c 2}$ defines the power transfer between the $\mathrm{SC}_{1}$ and $\mathrm{SC} 2$ via the $\mathrm{AC}$ side and the power will be fed to the $\mathrm{AC}$ grid, $P_{g}=P_{a c l}+P_{a c 2}$. Reconsidering the above scenario, but this time with $P_{a c 2}>P_{a c l}, P_{a c 1}$ defines the power transfer between the SC1 and SC2 via the AC side and the power to be fed to the AC grid $\left|P_{a c l}-P_{a c 2}\right|$. When the power flow directions in the $\mathrm{SC}_{1}$ and $\mathrm{SC}_{2}$ are in the same direction, no power will be exchanged between the $\mathrm{SC}_{1}$ and $\mathrm{SC}_{2}$ via the $\mathrm{AC}$ side; instead the whole power transfer will be via the DC side, and individual subconverters and the $\mathrm{AC}$ grid. Considering a three-winding transformer model, the $\mathrm{SC}_{1}$ and $\mathrm{SC}_{2}$ of the two-port converter can be described with reference to the secondary and tertiary sides as:

$$
\begin{aligned}
& L_{T 1} d i_{a b c 1} / d t+R_{T 1} i_{a b c 1}=v_{a b c g}^{s}-\frac{1}{2}\left(V_{d c 1}-V_{d c 2}\right)-\frac{1}{2}\left(v_{l a b c 1}-v_{u a b c 1}\right) \\
& L_{T 2} d i_{a b c 2} / d t+R_{T 2} i_{a b c 2}=v_{a b c g}^{t}-\frac{1}{2} V_{d c 2}-\frac{1}{2}\left(v_{l a b c 2}-v_{u a b c 2}\right)
\end{aligned}
$$

where $\quad R_{T 1}=1 / 2 R_{d 1}+R_{s}+R_{p s}$ and $R_{T 2}=1 / 2 R_{d 2}+R_{t}+R_{p t} \quad$ and $L_{T 1}=1 / 2 L_{d 1}+L_{s}+L_{p s}$ and $L_{T 2}=1 / 2 L_{d 2}+L_{t}+L_{p t}$ stand for the transformer resistances and inductances referred to the secondary and tertiary sides; $R_{p s}$ and $R_{p t}$, and $L_{p s}$ and $L_{p t}$ stand for the resistance and inductance of the primary windings referred to secondary and tertiary sides; $R_{s}$ and $R_{t}$, and $L_{s}$ and $L_{t}$ are resistances and inductances of the secondary and secondary windings. Because of the asymmetrical nature of the $\mathrm{SC}_{1}$ and $\mathrm{SC}_{2}$ in Fig. 1 (a), the DC components $1 / 2\left(V_{d c l}-V_{d c 2}\right)$ and $1 / 2 V_{d c 2}$ cancel with those in the converters' terminal voltages $v_{a b c g}^{s}$ and $v_{a b c g}^{t}$ when seen from secondary and tertiary sides of the $\mathrm{SC}_{1}$ and $\mathrm{SC}_{2}$. Thus, $v_{a b c g}^{s}-\frac{1}{2}\left(V_{d c 1}-V_{d c 2}\right) \approx v_{a b c s}$ and $v_{a b c g}^{t}-\frac{1}{2} V_{d c 2} \approx v_{a b c t}$, and since the DC free terminal voltages of the $\mathrm{SC}_{1}$ and $\mathrm{SC}_{2}$ can be expressed in terms of their corresponding upper lower arm voltages: $\frac{1}{2}\left(v_{l a b c 1}-v_{u a b c 1}\right) \approx v_{c 1}^{a b c}$ and $\frac{1}{2}\left(v_{l a b c 2}-v_{u a b c 2}\right) \approx v_{c 2}^{a b c}$. With these assumptions, (13) is transformed into $d-q$ as:

$$
\begin{aligned}
& d i_{d q 1} / d t=-R_{T 1} i_{d q 1} / L_{T 1}+\left(v_{d q s}-v_{c d q 1}-j \omega L_{T 1} i_{d q 1}\right) / L_{T 1} \\
& d i_{d q 2} / d t=-R_{T 2} i_{d q 2} / L_{T 2}+\left(v_{d q t}-v_{c d q 2}-j \omega L_{T 2} i_{d q 2}\right) / L_{T 2}
\end{aligned}
$$

Equation (14) indicates that two independent current controllers are needed for the $\mathrm{SC}_{1}$ and $\mathrm{SC}_{2}$ of the two-port converter in Fig. 1 Fig. 1(a). The current controllers to be incorporated into $\mathrm{SC}_{1}$ and $\mathrm{SC}_{2}$ can be expressed as:

$$
\begin{aligned}
& \lambda_{d q 1}=k_{p i 1}\left(i_{d q 1}^{*}-i_{d q 1}\right)+k_{i i 1} \int\left(i_{d q 1}^{*}-i_{d q 1}\right) d t \\
& \lambda_{d q 2}=k_{p i 2}\left(i_{d q 2}^{*}-i_{d q 2}\right)+k_{i i 2} \int\left(i_{d q 2}^{*}-i_{d q 3}\right) d t \\
& v_{c d q 1}=v_{d q s}-j \omega L_{T 1} i_{d q 1}-\lambda_{d q 1} \\
& v_{c d q 2}=v_{d q t}-j \omega L_{T 2} i_{d q 2}-\lambda_{d q 2}
\end{aligned}
$$

Therefore, the outer controllers that regulate d-axis voltage in case of islanding operation, or active power or DC voltage in case of grid connection, define $i_{d 1}^{*}$ and $i_{d 2}^{*}$, while $i_{q 1}^{*}$ and $i_{q 2}^{*}$ are defined from the outer controllers that regulate reactive power or AC voltage in grid connection case or q-axis voltage in case of islanding. The complete control systems used to regulate $\mathrm{SC}_{1}$ and $\mathrm{SC}_{2}$ of the MPCs being studied here are similar to the conventional power or DC voltage controlling converters of the modular converter based HVDC transmission systems. Also, a proportional-integral circulating current controller is implemented in each SC to suppress the $2^{\text {nd }}$ and $4^{\text {th }}$ harmonic currents in the MMC arms.

\section{SimUlations}

This section demonstrates the control flexibility of the multiport DC-DC and DC-AC in Fig. 1. Each -converter is modelled an average MMC model. The system simulation parameters are: 
arm reactors $\left(R_{d 1}=R_{d 2}=0.5 \Omega, R_{d 3}=0.4 \Omega ; L_{d 1}=L_{d 2}=45 \mathrm{mH}\right.$ and $\left.L_{d 3}=30 \mathrm{mH}\right)$; cell capacitances $\left(C_{m l}=C_{m 2}=10 \mathrm{mF}\right.$ and $\left.C_{m 3}=8 \mathrm{mF}\right)$; interfacing transformer $\left(R_{p}=R_{s}=R_{t}=0.002 \mathrm{pu}\right.$, $L_{p}=L_{s}=L_{t}=0.05 \mathrm{pu}, 1300 \mathrm{MVA}$ and $\left.400 \mathrm{kV} / 300 \mathrm{kV} / 300 \mathrm{kV}\right)$; and $400 \mathrm{kV}$ AC grid with $15000 \mathrm{MVA}$ three-phase short circuit fault level and $X / R=15$. In this demonstration, the SCs of the MPCs in Fig. 1 employs DC voltage, active power and reactive power controllers in the outer load; inner fundamental current control in synchronous reference frame; and a controller for circulating current suppression. The overall model (power circuit and control systems) is implemented in Matlab-Simulink.

\section{A) Two-port converter}

\section{1) Four quadrant operation:}

Fig. 2 displays simulation waveforms that illustrate the active powers exchange between the $\mathrm{SC}_{1}$ and $\mathrm{SC}_{2}$ of the two-port system being studied and $\mathrm{AC}$ grid. System operating conditions are summarised as follows:

- During interval $0 \leq t<0.8 s$, the $\mathrm{SC}_{1}$ is instructed to control its active power exchange with the AC grid at -390MW (negative sign entails the power flow direction is from AC to DC).

- At $t=0.8 \mathrm{~s}, \mathrm{SC}_{1}$ varies and reverses its power flow exchange with the AC grid to be $-390 \mathrm{MW}$ to $650 \mathrm{MW}$.

- During interval $0 \leq t<1.6 s$, the $\mathrm{SC}_{2}$ controls its output active power exchange with the AC grid at $390 \mathrm{MW}$ (direction from $\mathrm{DC}$ to $\mathrm{AC}$ ).

- At $t=1.6 \mathrm{~s}, \mathrm{SC}_{2}$ reverses its active power flow from $390 \mathrm{MW}$ to $-650 \mathrm{MW}$.

Fig. 2 (a) shows active power contribution of the $\mathrm{SC}_{1}$ and $\mathrm{SC}_{2}$, and the total active power the MPC exchanges with the AC grid. Observe that when the MPC exchanges zero power with AC grid, the $\mathrm{SC}_{1}$ and $\mathrm{SC}_{2}$ have the same power magnitude but with opposite polarities. This means that under this operating condition, the MPC in Fig. 1 (b) operates as the auto DC transformer proposed in [19]. Fig. 2 (b) displays the DC powers of the $\mathrm{SC}_{1}$ and $\mathrm{SC}_{2}$ and that being exchanged at the $\mathrm{HV}$ and $\mathrm{LV}$ DC terminals of the MPC. Fig. 2 (c) shows the DC currents in the $\mathrm{SC}_{1}$ and $\mathrm{SC}_{2}$ arms, and in the DC terminals of the $\mathrm{HV}$ and LV sides. Notice that although a large DC current is observed in the LV DC terminal, no sub-converter is exposed to excessive current stress.

2)Power control between DC terminals when AC terminal is connected to a passive load:
This section displays simulation waveforms when MPC in Fig. 1 (a) operates from a symmetrical DC link voltage of $\pm 600 \mathrm{kV}$, with its AC side connected to passive load. The passive load connected to ac side is 200MW and 50MVAr, and the secondary and tertiary windings of the 3 -winding transformer are connected to the $\mathrm{SC}_{1}$ and $\mathrm{SC}_{2}$. The $\mathrm{SC}_{1}$ is operated in an islanding mode that sets stiff $\mathrm{AC}$ voltage across the passive load, and the $\mathrm{SC}_{2}$ locks to the $\mathrm{AC}$ voltage established by the $\mathrm{SC}_{1}$ and controls active power as explained earlier. In time interval $0 \leq t<0.6 \mathrm{~s}$, the $\mathrm{SC}_{2}$ controls its active power $P_{a c 2}$ at zero. At $t=0.6 \mathrm{~s}$, it increases $P_{a c 2}$ from 0 to $380 \mathrm{MW}$. (a) displays the active powers of the $\mathrm{SC}_{1}$ and $\mathrm{SC}_{2} P_{a c l}$ and $P_{a c 2}$, and the power consumed in the AC island (passive AC load). Fig.3 (b) presents the DC powers being exchanged between the $\mathrm{SC}_{1}$ and $\mathrm{SC}_{2}$, including that in the LV and HV DC terminals. Fig. 3 (c) presents $\mathrm{DC}$ components of the arm currents of the $\mathrm{SC}_{1}$ and $\mathrm{SC}_{2}$, and the DC currents in the LV and HV DC terminals. Notice that when the $\mathrm{SC}_{2}$ controls its active power at zero, zero currents are seen in its arms, and in this period $I_{d c 2}=-I_{d c l}$; thus $I_{d 2}=0$, $P_{d c}$ (upper $)=P_{d c}($ lower $)$, see Fig.3 (a) to (c). The results in Fig.3 demonstrate the increased control flexibility of the MPC when its $\mathrm{AC}$ side is connected to passive AC network with no generation.

\section{B) Three-port converter}

Fig. 4 displays simulation traces for the three-port converter in Fig. 1 (b), with the power set-points of the sub-converters 1, 2 and 3 are $P_{a c l}=-650 \mathrm{MW}, P_{a c 2}=325 \mathrm{MW}$ and $P_{a c}=325 \mathrm{MW}$. At $t=0.8 \mathrm{~s}, 1.6 \mathrm{~s}$ and $2 \mathrm{~s}$, sub-converters 1,2 and 3 have varied their set-points from $-650 \mathrm{MW}$ to $+1040 \mathrm{MW}, 325 \mathrm{MW}$ to $325 \mathrm{MW}$ and $325 \mathrm{MW}$ to $-455 \mathrm{MW}$ respectively. Fig.4 (a) shows that in the time interval $t<0.8 \mathrm{~s}$, the MPC in Fig. 1 Fig. 1(b) operates as a typical auto DC-transformer with multiple DC outputs and zero active power injection into the AC grid. Fig.4 (b) shows the DC powers at different DC terminals, including at $\mathrm{SC}_{1}$. Fig.4 (a) and (b) confirm that the power distributions in the three-port converter obey to the same fundamentals as the twoport converter, i.e., $P_{a c l}=(n-1) / n P_{d c 1}$ and $P_{g}=P_{a c 1}+P_{a c 2}+P_{a c 3}$. It worth emphasizing that even though the DC power of $\mathrm{SC}_{2}$ changes at $t=0.8 s$ with $P_{a c l}$ (as a results of internal DC power transfer via the DC side), the currents in the arms of subconverter 2 remain to be distinctly determined by $P_{a c 2}$, see Fig. 4 (a), (b) and (c). Whilst the DC power and currents of the $\mathrm{SC}_{3}$ are purely defined by $P_{a c 3}$. Fig.4 (c) shows that the DC link currents and DC components of the arm currents of the different subconverters and their distributions in $\mathrm{SC}_{1}$ and $\mathrm{SC}_{2}$ obey the same principles has been established for the two-port converter discussed in sections III and IV-A.

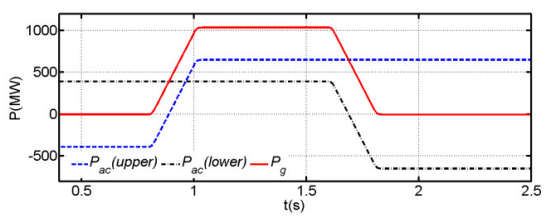

(a) $P_{a c}$ (upper) and $P_{a c}($ lower), and $\mathrm{AC}$ power being exchanged with the AC grid, $P_{g}$

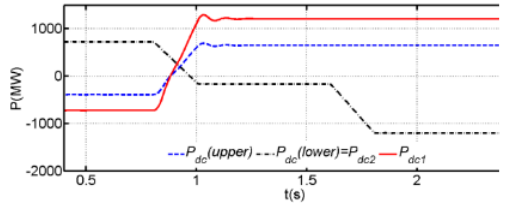

(b) $P_{d c}$ (upper) and $P_{d c}($ lower $)$, and DC power at HV and LV DC terminals, $P_{d c l}$ and $P_{d c 2}$

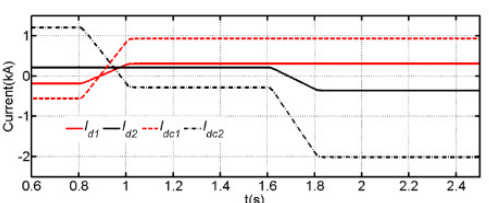

(c) DC currents in the arms of the $\mathrm{SC}_{1}$ and $\mathrm{SC}_{2}, I_{d l}$ and $I_{d 2}$, and in the HV and LV DC terminals, $I_{d c l}$ and $I_{d c 2}$

Fig. 2: Illustration of power control flexibility of the two-port converter when its HV and LV DC terminals are fed from active DC networks ( $V_{d c l}=1300 \mathrm{kV}$ and $V_{d c 2}=600 \mathrm{kV}$ ) and its AC side is attached to AC grid: (a) 


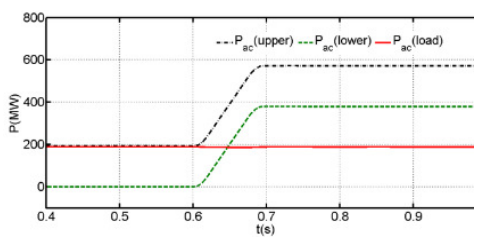

(a) Active powers of $\mathrm{SC}_{1}$ and $\mathrm{SC}_{2}$, $\mathrm{P}_{\mathrm{ac}}$ (upper) and $\mathrm{P}_{\mathrm{ac}}($ lower), and active power being consumed by the AC load

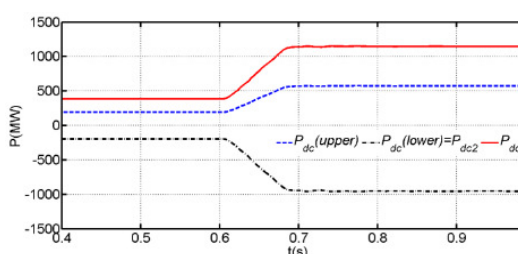

(b) DC powers of $\mathrm{SC}_{1}$ and $\mathrm{SC}_{2}, \mathrm{P}_{\mathrm{dc}}$ (upper) and $\mathrm{P}_{\mathrm{dc}}($ lower), and in the $\mathrm{HV}$ and $\mathrm{LV}$ DC terminals

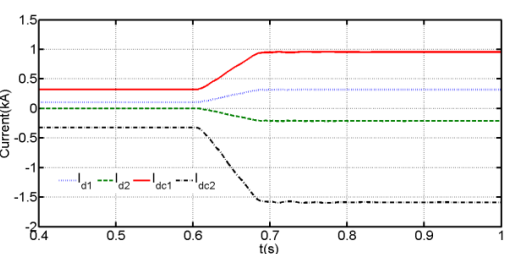

(c) DC currents in the arms of the $\mathrm{SC}_{1}$ and $\mathrm{SC}_{2}, \mathrm{I}_{\mathrm{d} 1}$ and $\mathrm{Id}_{\mathrm{d} 2}$ and in the $\mathrm{HV}$ and LV DC terminals

Fig. 3: Illustration of power control when the proposed MPC converter is fed from a symmetrical DC bus of $\pm 600 \mathrm{kV}$, with its AC side is attached to passive load.

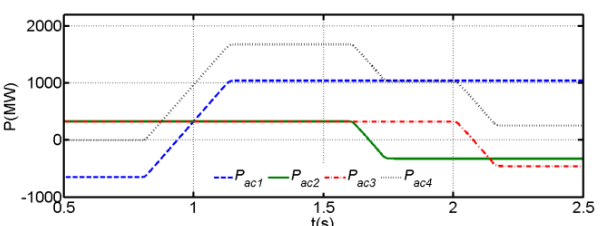

(a) Active powers of $\mathrm{SC}_{1}, \mathrm{SC}_{2}$ and $\mathrm{SC}_{3}$, and total active exchange with the $\mathrm{AC}$ grid

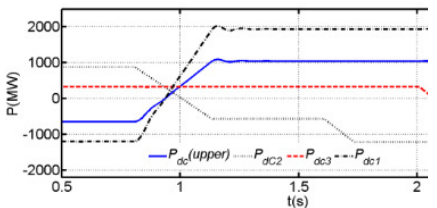

(b) DC powers of $\mathrm{SC}_{1}, \mathrm{SC}_{2}$ and $\mathrm{SC}_{3}$

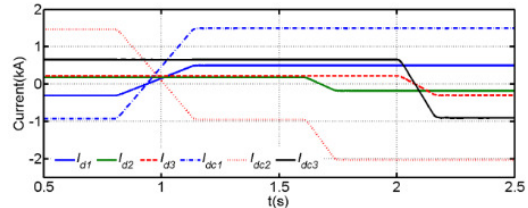

(c) DC currents in the arms of $\mathrm{SC}_{1}, \mathrm{SC}_{2}$ and $\mathrm{SC}_{3}$ and in their DC busses

Fig. 4: Illustrating of the power control in three-port converter when all its DC terminals are connected to active DC networks, with $V_{d c l}=1300 \mathrm{kV}$, $V_{d c 2}=600 \mathrm{kV}$ and $V_{d c 3}=500 \mathrm{kV}$, and its $\mathrm{AC}$ side is connected $\mathrm{AC}$ grid.

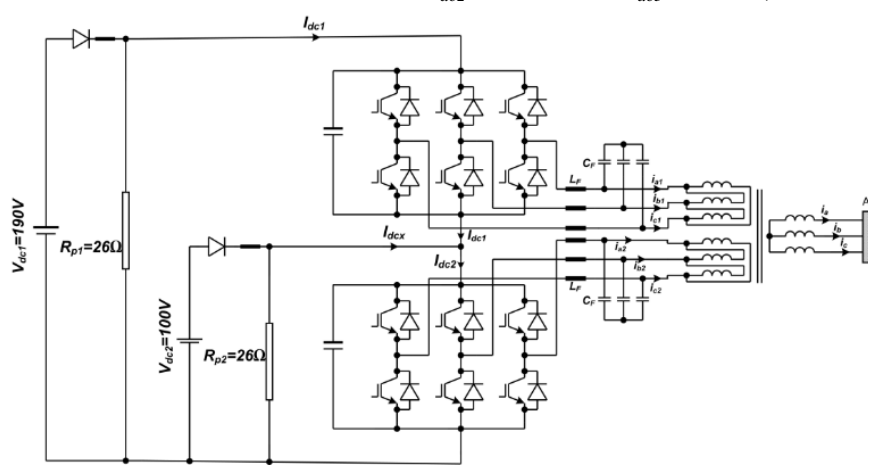

(a)

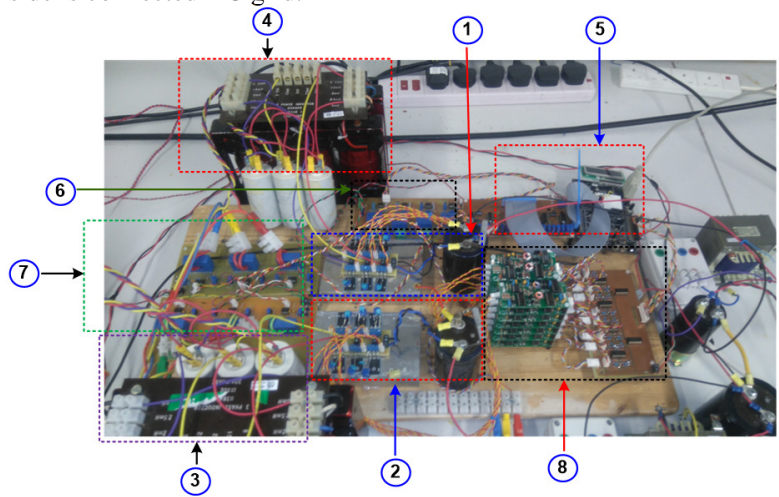

(b)

Fig. 5. (a) and (b) are details of the prototype (diagram and photo) when the $\mathrm{SC}_{1}$ and $\mathrm{SC}_{2}$ are realised by the conventional two-level converters:, with 1 and 2 signify $\mathrm{SC} 1$ and $\mathrm{SC} 2 ; 3$ and 4 signify AC filters of the $\mathrm{SC}_{1}$ and $\mathrm{SC}_{2} ; 5$ is a microcontroller employed to program PWM and control systems; 6 and 7 are voltage and current senors; and 8 depicts the gate-drives and circuity that generates complementary PWM signal.

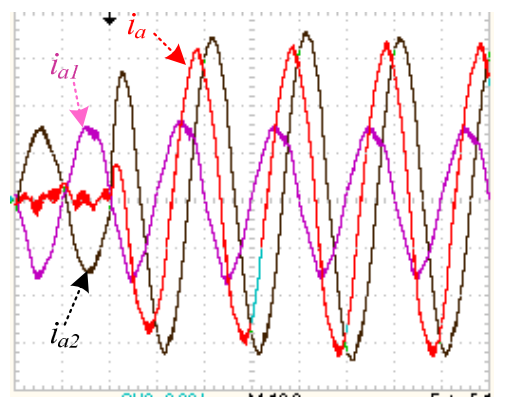

(a)

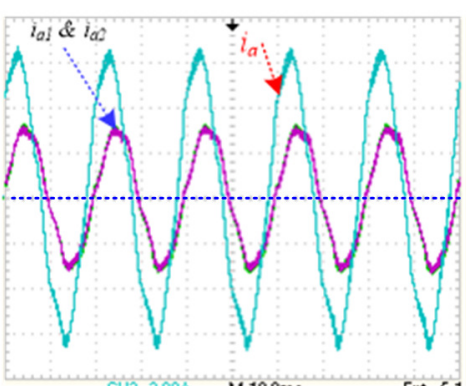

(b)

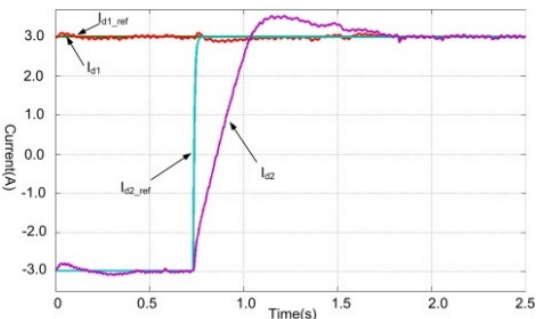

(c)

Fig. 6: Experimental demonstartion of the control flexibility of MPC converter when q-axis current orders of the $\mathrm{SC}_{1}$ and $\mathrm{SC}_{2}$ are held at zero $\left(i_{q 1}=i_{q 2}=0\right)$. and $i_{d l}=3 \mathrm{~A}$ and step change is applied to $i_{d 2}$ from $-3 \mathrm{~A}$ to $-3 \mathrm{~A}$ :

(a) represents snapshot of the $\left(i_{a l}, i_{a 2}\right.$ and $\left.i_{a}\right)$ zoomed around the time of application of step change to $i_{d 2}$ and (b) is the snapshot of the $\left(i_{a l}\right.$, $i_{a 2}$ and $\left.i_{a}\right)$ when the system has reached the steady-state condition, (c) represents the direct axis currents of the $\mathrm{SC}_{1}$ and $\mathrm{SC}_{2}$ for the latter case. In both cases, the scales are maintained at $(10 \mathrm{~ms} / \mathrm{div}$ and $2 \mathrm{~A} / \mathrm{div})$

\section{EXPERIMENTAL VALIDATION}

This section presents experimental validation of the theoretical discussions and simulation results of the MPC presented in sections II and IV using experimental results obtained from the scaled-down prototype of the two-port converter in Fig.5 (a) and (b). Although all the previous discussions assume that the $\mathrm{SC}_{1}$ and $\mathrm{SC}_{2}$ of the MPC are MMCs, the experimental prototype realizes these subconverters by the two-level voltage source converters in
Fig.5 (a) and (b). To realize bidirectional power flow using single-quadrant DC power supplies, a diode and an inductor and resistances $R_{p 1}$ and $R_{p 2}$ are added as shown in Fig.5 (a). The resistances are selected to ensure that the inequalities $I_{d c 1} R_{p 1}<V_{d c l}$ and $I_{d c x} R_{p 2}<V_{d c 2}$ are satisfied under all operating conditions. In this way, $V_{d c 1}$ and $V_{d c 2}$ remain virtually constant at $190 \mathrm{~V}$ and $100 \mathrm{~V}$ as the $\mathrm{SC}_{1}$ and $\mathrm{SC}_{2}$ vary their current set-points. Table I shows parameters of the prototype. 
Table I: Test rig parameters

\begin{tabular}{|l|c|}
\hline Parameter & Value \\
\hline Grid voltage & $45 \mathrm{Vrms}$ \\
& $50 \mathrm{~Hz}$ \\
\hline dc voltage of the HV side $\left(V_{d c l}\right)$ & $190 \mathrm{~V}$ \\
\hline dc voltage of the LV side $\left(V_{d c 2}\right)$ & $100 \mathrm{~V}$ \\
\hline ac side filtering inductance $\left(L_{F}\right)$ & $2.6 \mathrm{mH}$ \\
\hline ac filtering capacitance $\left(\mathrm{C}_{\mathrm{F}}\right)$ & $30 \mu \mathrm{F}$ \\
\hline Transformer voltage ratio & $400 / 415 / 415$ \\
\hline Carrier frequency & $2.4 \mathrm{kHz}$ \\
\hline DC link capacitances of SC1 and SC2 & $2.2 \mathrm{mF}$ \\
\hline
\end{tabular}

\section{A)-Control flexibility}

Fig.6 displays experimental waveforms of the two-port converter in Fig. 6 when its operating conditions as follows: $\mathrm{SC}_{1}$ regulates its $\mathrm{d}$ and $\mathrm{q}$ axis currents at $i_{d l}=3 \mathrm{~A}$ and $i_{q 1}=0$; and $\mathrm{SC}_{2}$ varies its d-axis current $i_{d 2}$ from $-3 \mathrm{~A}$ to $3 \mathrm{~A}$, and its $\mathrm{q}$-axis current is controlled at zero $\left(i_{q 2}=0\right)$.

Fig.6 (a) and (b) show phase 'a' currents of the $\mathrm{SC}_{1}$ and $\mathrm{SC}_{2}$ (black and purple) and total current being injected into AC grid (in red). Fig.6 (c) displays the d-axis currents of the $\mathrm{SC}_{1}$ and $\mathrm{SC}_{2}$ overlaid on their respective reference currents. Notice that the phase currents and their d-q components follow the current commands given to the $\mathrm{SC}_{1}$ and $\mathrm{SC}_{2}$, with zero grid current is observed when $i_{d 2}=-i_{d l}$. This point out that under such operating condition, the MPC in Fig.5 operates as an auto DC-transformer described in [19].

\section{CONCLUSIONS}

This paper has investigated several MPCs capable of operating as DC-DC and DC-AC converters and offer multiple DC and AC terminals. Detailed discussions of the presented MPCs demonstrate their suability for control of power and DC voltage, and DC voltage matching and tapping in complex medium and high-voltage DC grids. Comprehensive discussions, simulations and experimental waveforms have confirmed the enhanced control flexibility of the presented MPC, which is vital for resolving several outstanding control issues in future DC grids.

\section{ACKNOWLEDGMENT:}

This project was funded by the Deanship of Scientific Research (DSR) at King Abdulaziz University, Jeddah, under grant no. (RG-5-135-38). The authors, therefore, acknowledge with thanks DSR For technical and financial support.

\section{REFERENCES}

1] M. O. Khan, "Analyzing the effects of converter and DC line outages due to Distributed Voltage Control in AC-MTDC Distribution Network " International Journal of Renewable Energy ResearchIJRER, vol. 8, no. 8, pp. 1740-1748, 2018.

[2] G. P. Adam, K. H. Ahmed, D. Holliday, S. J. Finney, G. M. Burt, and B. W. Williams, "Controlled transition bridge multilevel converter," in 2016 IEEE International Conference on Renewable Energy Research and Applications (ICRERA), 2016, pp. 794-798.

[3] G. P. Adam, K. H. Ahmed, and B. W. Williams, "Hybrid multilevel converter with dc side H-bridge chain links," in Renewable Energy Research and Applications (ICRERA), 2013 International Conference on, 2013, pp. 1002-1006.

[4] G. P. Adam, S. J. Finney, and B. W. Williams, "Enhanced control strategy of full-bridge modular multilevel converter," in 2015 International Conference on Renewable Energy Research and Applications (ICRERA), 2015, pp. 1432-1436.

[5] A. M. Omran, K. H. Ahmed, M. S. Hamad, and I. F. Al-Arabawy, "Interconnection between different DC technologies at multi-terminal HVDC network," in Renewable Energy Research and Application (ICRERA), 2014 International Conference on, 2014, pp. 295-300.

[6] K. Rouzbehi, Z. Jiebei, Z. Weiyi, G. B. Gharehpetian, A. Luna, and P. Rodriguez, "Generalized voltage droop control with inertia mimicry capability - step towards automation of multi-terminal HVDC grids," in 2015 International Conference on Renewable Energy Research and Applications (ICRERA), 2015, pp. 1556-1561.

[7] S. Li, F. Xingang, E. Alonso, M. Fairbank, and D. C. Wunsch, "Neural-network based vector control of VSCHVDC transmission systems," in 2015 International Conference on Renewable Energy Research and Applications (ICRERA), 2015, pp. 173-180.

[8] A. A. J. Far, M. Hajian, D. Jovcic, and Y. Audichya, "High-power modular multilevel converter optimal design for DC/DC converter applications," IET Power Electronics, vol. 9, no. 2, pp. 247-255, 2016.

[9] M. Corti, E. Tironi, and G. Ubezio, "DC Networks Including Multiport DC/DC Converters: Fault Analysis," IEEE Transactions on Industry Applications, vol. PP, no. 99, pp. 1-1, 2016.

[10] R. Kondo, Y. Higaki, and M. Yamada, "Proposition and experimental verification of a bi-directional isolated DC/DC converter for battery charger-discharger of electric vehicle," in 2016 IEEE Applied Power Electronics Conference and Exposition (APEC), 2016, pp. 17131720 .

[11] P. Gaur, N. Soren, and D. Bhowmik, "Impact Assessment of Vehicleto-grid Technology in LFC of Multi-area Solar-thermal Power System," International Journal of Renewable Energy ResearchIJRER, vol. 8, no. 3, pp. 1582-1590, 2018.

[12] M. Moazzami, J. Moradi, H. Shahinzadeh, G. B, Gharehpetian, and H. Mogoei, "Optimal Economic Operation of Microgrids Integrating Wind Farms and Advanced Rail Energy Storage System," International Journal of Renewable Energy Research-IJRER, vol. 8, no. 2, 2018.

[13] R. C, C. H. Basha, and S. odofin, "A Review on Non-isolated Inductor Coupled DC-DC Converter for Photovoltaic Grid-Connected Applications," vol. 7, no. 4, pp. 1571-1585, 2017.

[14] B. Zhao, Q. Song, J. Li, X. Xu, and W. Liu, "Comparative Analysis of Multilevel-High-Frequency-Link and Multilevel-DC-Link DC\&\#8211;DC Transformers Based on MMC and Dual-Active Bridge for MVDC Application," IEEE Transactions on Power Electronics, vol. 33, no. 3, pp. 2035-2049, 2018.

[15] P. Li, G. P. Adam, S. J. Finney, and D. Holliday, "Operation Analysis of Thyristor Based Front-to-Front Active-Forced-Commutated Bridge DC Transformer in LCC and VSC Hybrid HVDC Networks," IEEE Journal of Emerging and Selected Topics in Power Electronics, vol. PP, no. 99, pp. 1-1, 2017.

[16] D. Jovcic and H. Zhang, "Dual Channel Control With DC Fault Ride Through for MMC-Based, Isolated DC/DC Converter," IEEE Transactions on Power Delivery, vol. 32, no. 3, pp. 1574-1582, 2017.

[17] Y. Jie, H. Zhiyuan, P. Hui, and T. Guangfu, "The Hybrid-Cascaded DC\&\#x2013;DC Converters Suitable for HVdc Applications," Power Electronics, IEEE Transactions on, vol. 30, no. 10, pp. 53585363, 2015

[18] I. A. Gowaid, G. P. Adam, B. W. Williams, A. M. Massoud, and S. Ahmed, "The transition arm multilevel converter - A concept for medium and high voltage DC-DC transformers," in 2015 IEEE International Conference on Industrial Technology (ICIT), 2015, pp. 3099-3104.

[19] A. Schon and M. M. Bakran, "High power HVDC-DC converters for the interconnection of HVDC lines with different line topologies," in Power Electronics Conference (IPEC-Hiroshima 2014 - ECCEASIA), 2014 International, 2014, pp. 3255-3262.

[20] S. Kenzelmann, D. Dujic, F. Canales, Y. R. De Novaes, and A. Rufer, "Modular DC/DC converter: Comparison of modulation methods," in Power Electronics and Motion Control Conference (EPE/PEMC), 2012 15th International, 2012, pp. LS2a.1-1-LS2a.1-7.

[21] I. A. Gowaid, G. P. Adam, A. M. Massoud, S. Ahmed, D. Holliday, and B. W. Williams, "Quasi Two-Level Operation of Modular Multilevel Converter for Use in a High-Power DC Transformer With DC Fault Isolation Capability," Power Electronics, IEEE Transactions on, vol. 30, no. 1, pp. 108-123, 2015.

[22] I. A. Gowaid, G. P. Adam, A. M. Massoud, S. Ahmed, and B. W. Williams, "Hybrid and Modular Multilevel Converter Designs for Isolated HVDC-DC Converters," IEEE Journal of Emerging and Selected Topics in Power Electronics, vol. 6, no. 1, pp. 188-202, 2018.

[23] S. Ray, N. Gupta, and R. A. Gupta, "Prototype Development and Experimental Investigation on Cascaded Five-Level Inverter Based Active Filter for Large-Scale Grid-tied Photovoltaic" International Journal of Renewable Energy Research-IJRER, vol. 8, no. 3, pp. 1800-1811, 2018 